Occupational health

\section{Identification of research priorities in occupational health}

\section{S lavicoli, B Rondinone, A Marinaccio, M Fingerhut}

\section{A discussion of national priority setting systems}

$l^{n}$ recent decades far-reaching national efforts to set priorities for research in the sector of occupational safety and health (OSH) have led to redefinitions and shifts in national policies and priorities, with wide-scale involvement of all concerned-public and social bodies, occupational health and safety experts, companies, trade unions, public and private insurance agencies. The benefit of establishing national priorities in the OSH sector is clear from the success of several national stakeholder efforts to focus research and funding in key topical areas of occupational health, based on judgements that indicate the likelihood of addressing serious occupational health and safety problems. Here we describe the methods, results, and impact of national priority setting systems created by the National Institute for Occupational Safety and Health (NIOSH) in the USA, the National Institute for Occupational Safety and Prevention (ISPESL) in Italy, the British Occupational Health Research Foundation (BOHRF) in the United Kingdom, the European Agency for Safety and Health at Work for Europe, the University of Amsterdam in the Netherlands, the National Institute for Industrial Health in Japan, and the National Institute for Occupational Safety and Health in Malaysia. ${ }^{1-7}$ We focus mainly on European and North American studies, analysing their approaches to bringing together the concerned parties, looking at the measures taken to implement the priority decisions, and assessing the impact of the efforts.

Most national systems used the Delphi technique-pure or modifiedwhich involves an iterative process of two or more cycles of discussions or questionnaires, until the personal assessments of a panel of experts converge in a group consensus. The various countries selected their experts differently, reflecting the intrinsically multidisciplinary character of the OSH sector. In general, with a view to future impact, the countries included among the stakeholders were those likely to be affected by the research, as well as the researchers themselves. This approach contributed to substantial impact in the American and Italian efforts, and led to success in the Netherlands as well. The selection of different groups of stakeholders in the individual countries was influenced by national sociocultural factors and resulted in different choices of priorities to be emphasised. Some national efforts focused on research; others were dedicated to transferability of research into widespread use in practice in the country.

In the first round of questionnaires or discussions, the Delphi technique leaves the participants free to list what they consider priority research areas. However, the European Agency provided countries with a standard form and chose as its priorities the topics most frequently listed in the National Reports from the Member States. The participants were not free to select the areas where they considered it necessary to extend knowledge in order to safeguard workers' health. Despite attempts to unify the data, the National Reports showed substantial differences among the Member States: different subjects were involved in the projects, different degrees of agreement were reached, and the proposed EU outline was followed closely by some, less closely by others. Some EU countries contacted only a limited number of institutions, and completed the data with information from their files, not adhering closely to the standard classification suggested by the European Agency.

Other national priority setting activities also diverged from the usual Delphi system: not all the systems gave a ranking for each topic; in some cases priority was established for sub-items in relation to their macro-area. One macroarea designated for attention in four of the seven national efforts is the incidence and prevalence of selected occupational diseases, identified as needing research by the UK, USA, Italy, and Malaysia. All four of these systems listed these three sub-items as priorities: occupational asthma, dermatitis, and accidents in the workplace. Differences in national choices reflected the degree of development of research in a sector. For example, occupational carcinogenesis was assigned top priority in the Italian system, whereas the US National Occupational Research Agenda (NORA) restricted the priority area to cancer research methods. Musculoskeletal disorders, psychosocial/work organisation/ stress, and special vulnerable work populations are reflected in all seven national research agendas. Injuries, dermatological disorders, and respiratory diseases are included in six national systems, and hearing loss is found in five of these.

Substantial impact has been achieved in several countries through creation and implementation of national priority setting systems. In 1996 NIOSH convened a series of national meetings to bring together all OSH stakeholders to create the National Occupational Research Agenda (NORA) which would guide OSH research into the next decade in the United States. ${ }^{8}$ To ensure that research in the 21 priority areas identified by the stakeholders would be encouraged, NIOSH established a NORA team for each priority area, consisting of about 15 members, with about half from outside NIOSH. These teams developed national research agendas for the particular priority areas, organised national conferences, stimulated research, and produced useful information (http://www2a.cdc.gov/ NORA/default.html). NORA has been successful in stimulating funding and partnerships for new research needed to address the problems of workplace injuries and illnesses: from 1996, when NORA was set up, to 2003, NIOSH investment in the 21 priority areas increased from 15.4 to 94.3 million dollars. Besides the NIOSH investments, other partnering US federal agencies have awarded research funding to competitive academic scientific proposals in the NORA areas, reaching more than 30 million dollars in 2003.

The national stakeholder effort conducted by ISPESL in Italy in 2000 has also had considerable impact. It extensively involved the scientific community, the national health service, and various "social" bodies, and helped redefine the Institute's plans for further investigation of topics related to emerging risk. This led the Ministry of Health to give absolute priority to financing research into occupational carcinogenesis, allocating $33 \%$ of the budget to this topic in 2002. Next in line are themes related to low dose and multiple exposure $(23 \%)$, the quality of air and the indoor environment (17\%), biological agents (14\%), and the healthcare and hospital sector (13\%). 
The European Agency has set aside funds for further work on the topics assigned priority in the 1998 priority setting effort. Since 2000, each year's European Week-the information campaign designed to promote health and safety at work in the $15 \mathrm{EU}$ Member States-has focused on the priority topics identified. The European Week's themes have been musculoskeletal disorders (2000), accidents at work (2001), stress at work (2002), and handling dangerous substances (2003).

In the United Kingdom, the British Occupational Health Research Foundation has assigned a large part of its research budget to the topics that were given priority. Current research at the BOHRF is focused on musculoskeletal disorders and rehabilitation techniques, aimed at restoring workers' health in the shortest possible time so they can return to work, and on intervention techniques for acute cases to prevent chronic illness. Numerous other projects are nearing completion, regarding, for example, methods to reduce stress by reorganising work, and strategies to eliminate occupational asthma and its causes.

The successes of these seven national agendas may encourage occupational safety and health institutions in other countries to sponsor broad stakeholder efforts to identify national priority topics for which focused funding and research efforts could make substantial contributions to reduce occupational illness and injury.

Occup Environ Med 2005;62:71-72.

doi: 10.1136/oem.2004.015487

\section{Authors' affiliations}

S lavicoli, B Rondinone, A Marinaccio, ISPESL National Institute for Occupational Safety and Prevention, Rome, Italy

F Marilyn, NIOSH National Institute for

Occupational Safety and Health, Washington, DC, USA

Correspondence to: Dr S lavicoli, ISPESL, National Institute for Occupational Safety and Prevention, Via Fontana Candida, 1, 00040

Monteporzio Catone, Rome, Italy; seriav@iol.it

\section{Mental challenge in the workplace and risk of dementia in old age: is there a connection?}

\section{R S Wilson}

\section{Commentary on the paper by Seidler et al (Occup Environ Med, December 2004)*}

D ementia is among the most feared consequences of growing old, and with the aging of the generation born after World War II, its prevalence is expected to increase in most industrialised nations in the coming decades. Cognitive decline and dementia in late life are the result of multiple environmental and genetic risk factors interacting with multiple age related pathological changes taking place in the brain. The good news is that recent studies have identified a range of lifestyle factors associated with risk of dementia, including characteristic levels of cognitive, social, and physical activity and proneness to experience negative

*Seidler A, Nienhaus A, Bernhardt T, et al. Psychosocial work factors and dementia. Occup Environ Med 2004;61:962-71. emotions, suggesting that some proportion of risk may be modifiable.

In the December 2004 issue of Occupational and Environmental Medicine, Seidler and colleagues report an association between psychosocial features of the workplace environment and risk of dementia, with decreased risk in persons with more cognitively and socially challenging working conditions. ${ }^{1}$ The finding is noteworthy because few previous studies have examined the relation of workplace activities to risk of dementia in old age.

Perhaps the first question we should ask about the finding is whether it is valid. Seidler and colleagues ${ }^{1}$ selected dementia cases from medical records, which could bias results because many older persons with dementia do not come to medical attention, and those who do appear to differ from those who

\section{REFERENCES}

1 NIOSH. National occupational research agenda, US DHHS/CDC/National Institute for Occupational Safety and Health (NIOSH) Publication 96-115. Cincinnati, OH: NIOSH, 1996

2 lavicoli S, Marinaccio A, Vonesch N, et al. Research priorities in occupational health in Italy. Occup Environ Med 2001;58:325-9.

3 Harrington JM. Research priorities in occupational medicine: a survey of United Kingdom medical opinion by the Delphi technique. Occup Environ Med 1994;51:289-94.

4 European Agency for Safety and Health at Work. Future Occupational Safety and Health Research Needs and Priorities in the Member States of the European Union, Bilbao, 2000.

5 van der Beek AJ, Frings-Dresen MHW, van Dijk FJH, et al. Priorities in occupational health research: a Delphi study in the Netherlands. Occup Environ Med 1997;54:504-10.

6 Sadhra S, Beach JR, Aw T-C, et al. Occupational health research priorities in Malaysia: a Delphi study. Occup Environ Med 2001;58:426-31.

7 Araki S, Tachi M. National occupational health research priorities, agenda and strategy of Japan: invited report in NORA Symposium 2001, USA. Industrial Health 2003;41:49-54.

8 Rosenstock L, Olenec C, Wagner GR. The National Occupational Research agenda: a model of broad stakeholder input into a priority setting. Am J Public Health 1998;88:353-6.

do not. In addition, although the crosssectional case-control design of the study is a relatively cost-effective way to identify potential risk factors for dementia, a longitudinal cohort design has the advantage of collecting exposure data before dementia onset, so that results do not depend on the comparability of cases with controls or of informant-report (of job history) with self-report. Prospective studies have not examined psychosocial working conditions in detail like Seidler and colleagues, ${ }^{1}$ but global ratings of the cognitive demands and occupational prestige of work have found decreased risk of dementia associated with more cognitively demanding and prestigious jobs, ${ }^{2}$ consistent with their findings.

How might a challenging occupation help protect against the development of dementia in old age? Seidler and colleagues $^{1}$ suggest several possibilities. One is that decades before the appearance of clinically evident dementia, symptoms of the underlying disease might be affecting behaviour in the workplace. The onset of Alzheimer's disease, the most common cause of dementia, is indeed insidious. A prodromal period characterised by mild cognitive impairment precedes the appearance of manifest dementia, but the duration of this period is probably only a few years, ${ }^{3}$ and almost certainly not a few decades. Because most dementia develops after the age of 70, very early preclinical manifestations are unlikely to explain the relation of occupational history to dementia risk. 
Occupations differ in risk of exposure to potentially neurotoxic agents, but Seidler and colleagues ${ }^{1}$ rightly point out that there is currently little evidence that such exposures can account for the relation between occupation and risk of dementia. The authors also consider the possibility that differing levels of work related stress might affect risk of cardiovascular disease and ultimately of dementia. Secondary analyses did not support this explanation, however.

The leading causes of dementia in old age are the accumulation of amyloidbeta and tau-postive neurofibrillary tangles in the brain and cerebral infarctions. These pathological lesions are commonly found in the brains of older persons who die without dementia, however. This suggests that some risk factors for dementia may work by affecting the accumulation of these lesions, whereas others may work by affecting the brain's capacity to tolerate these lesions, sometimes referred to as brain reserve. Extensive animal research has shown that environmental complexity is related to individual differences in adulthood in neurogenesis and synaptogenesis in brain regions critical for memory and thinking. According to the brain reserve theory, therefore, engagement in activities that are cognitively, socially, and physically stimulating somehow enhances brain reserve so that selected neural systems are more difficult to disrupt and more age related pathology is needed to impair the skills mediated by those systems. Support for this idea comes from a clinicopathological study of older Catholic clergy members in which the deleterious impact of Alzheimer's disease pathology on cognitive function was reduced in persons with more education relative to those with less. ${ }^{4}$ The results of Seidler and colleagues ${ }^{1}$ are consistent with the brain reserve hypothesis, as they note.

Finally, are we to conclude that persons whose work does not routinely involve cognitive challenges and social stimulation are destined to face a heightened risk of dementia in old age in exchange for their labours? A recent prospective study suggests not: the association of occupational prestige with risk of incident dementia was eliminated after controlling for late life engagement in cognitively stimulating activities, ${ }^{5}$ implying that it is the overall level of stimulating activity that is important, not whether it occurs during work or during leisure time and underscoring the particular importance of maintaining an active lifestyle in old age.

\section{ACKNOWLEDGEMENTS}

This research was supported by National Institute on Aging Grant R01 AG17917.

Occup Environ Med 2005;62:72-73.

doi: 10.1136/oem.2004.017905

Correspondence to: Dr R S Wilson, Rush Alzheimer's Disease Center, Rush University Medical Center, Armour Academic Center, 600 South Paulina, Suite 1038, Chicago, IL 60612 , USA; rwilson@rush.edu

\section{REFERENCES}

1 Seidler A, Nienhaus A, Bernhardt T, et al. Psychosocial work factors and dementia. Occup Environ Med 2004:61:962-71.

2 Evans DA, Hebert LE, Beckett LA, et al. Education and other measures of socioeconomic status and risk of incident Alzheimer's disease in a defined population of older persons. Arch Neurol 1997:54:1399-405.

3 Hall CB, Lipton RB, Sliwinski $M$, et al. A change point model for estimating the onset of cognitive decline in preclinical Alzheimer's disease. Stat Med 2000; 19:1555-66.

4 Bennett DA, Wilson RS, Schneider JA, et al. Education modifies the relation of $A D$ pathology to level of cognitive function in older persons. Neurology 2003;60:1909-15.

5 Wilson RS, Bennett DA, Bienias JL, et al. Cognitive activity and incident $A D$ in a population-based sample of older persons. Neurology 2002;59:1910-15. 